\title{
Ultrastructural Aspects of Apoptosis in Systemic Sclerosis Inflammatory Myopathy
}

\author{
Héctor J. Finol ${ }^{1}$, Héctor Luis Osorio-Vega², Radharani Dorta-Ledezma1, \\ Antonio Roschman-González ${ }^{1}$, Blanca Muller ${ }^{3}$, Israel Montes de Oca ${ }^{4}$ \\ ${ }^{1}$ Center for Electron Microscopy, Sciences Faculty, Caracas, Venezuela \\ ${ }^{2}$ Laboratory of Cellular and Molecular Pathology, Center for Experimental Medicine, Venezuelan Institute for Scientific Research, \\ Miranda, Venezuela \\ ${ }^{3}$ Dentistry Faculty, Central University of Venezuela, Caracas, Venezuela \\ ${ }^{4}$ Medicine Service No. 2, Caracas University Hospital, Caracas, Venezuela \\ Email: ^hector.finol@gmail.com
}

How to cite this paper: Finol, H.J., Osorio-Vega, H.L., Dorta-Ledezma, R., Roschman-González, A., Muller, B. and de Oca, I.M. (2018) Ultrastructural Aspects of Apoptosis in Systemic Sclerosis Inflammatory Myopathy. Microscopy Research, 6, 1-7. https://doi.org/10.4236/mr.2018.61001

Received: December 5, 2014

Accepted: January 12, 2018

Published: January 15, 2018

Copyright (c) 2018 by authors and Scientific Research Publishing Inc. This work is licensed under the Creative Commons Attribution International License (CC BY 4.0).

http://creativecommons.org/licenses/by/4.0/

\begin{abstract}
Muscle biopsies from two female patients with systemic sclerosis (SS) and an inflammatory myopathy were studied ultrastructurally in relation to the possible presence of apoptosis in skeletal muscle fibers. Undergoing apoptosis showed characteristic morphological features of this process, including chromatin aggregation as well as nuclear and sarcoplasmic partition into membrane bound-vacuoles (apoptotic bodies) which contained autophagosomes, mitochondria, isolated myofilaments and nuclear material. Vacuoles exhibited different diameters and were covered by single membranes, appearing beneath basement membrane. Apoptosis occurred in some fiber segments as in necrosis or included whole atrophied fibers. These results indicate that apoptosis coexists with necrosis in the inflammatory myopathy of SS.
\end{abstract}

\section{Keywords}

Apoptosis, Skeletal Muscle Fiber, Systemic Sclerosis, Inflammatory Myopathy, Ultrastructure

\section{Introduction}

Controversial evidence has been presented in several studies in relation to the occurrence of apoptosis in diseased skeletal muscle. Apoptosis was not found in dystrophinopathies, myotonic dystrophy and inflammatory myopathies such as polymyositis (PM), dermatomyositis and inclusion body myositis [1] [2] [3] [4]. Contrary to the result found in autoimmune diseases as in the mentioned inflammatory myopathies, there is an increasing body of evidences indicating that 
apoptotic cells may potentially help break immune tolerance to certain autoantigens and initiate autoimmune reactions [5] [6] [7] [8]. This could take place in autoimmune muscle diseases such as polymyositis and inclusion body myositis (IBM). Apoptosis has been observed in skeletal muscle biopsies obtained from patients with spinal muscular atrophies [1].

In ultrastructural studies of myositis and inflammatory myopathies associated with rheumatic diseases, it has not yet been described apoptosis in skeletal muscle fibers [9] [10] [11]. In the present work, we report ultrastructural evidences of apoptosis in SS inflammatory myopathy which coexists with the already described segmental necrosis [11].

\section{Materials and Methods}

Patients admitted to the study were attending the rheumatologic clinics at the Caracas University Hospital. The Ethics Committee of the Hospital approved the project and the subjects gave written consent. Patients (two women) had definite SS as assessed by Subcommittee for Scleroderma Criteria of the American Rheumatism Association [12]. Patients presented proximal muscular weakness and minimal muscle wasting. They showed no signs of concomitant rheumatic disorders. Antibodies to ribonuclearproteins (RNP) of the extractable nuclear antigens (ENA) were absent in all cases.

Light microscopic observation of quadriceps femoris muscle biopsies showed fiber atrophy with wide variation of fibers size, occasional necrotic fibers and mononuclear cell infiltration. For transmission electron microscopy, muscle biopsies were obtained. Each specimen was diced into 3 - 4 blocks about $1 \mathrm{~mm}$ long; they were fixed in $3 \%$ glutaraldehyde in phosphate buffer for $30 \mathrm{~min}$ at $\mathrm{pH}$ 7.4 and 320 mOsm, postfixed in $1 \% \mathrm{OsO}_{4}$ and embedded in epon resin. Sections were cut with a diamond knife in a Porter-Blum MT2-B ultramicrotome and stained with uranyl acetate and lead citrate. Sections were observed in a Jeol JEM-1011 transmission electron microscope, at an accelerating voltage of $80 \mathrm{kV}$.

\section{Results}

As it was described in a previous work [11], different degrees of fiber atrophy are evident in SS inflammatory myopathy with alterations in the sarcomeric structure and loss of elements of the sarcotubular system which varied from slight to severe (Figure 1(A)). In this Figure, the skeletal muscle fibers show atrophy with a widening of the subsarcolemmal and intermyofibrillar spaces. In these spaces fragments of the sarcotubular system ( $\mathrm{T}$ tubules and sarcoplasmic reticulum), and mitochondria with different morphology and degree of swelling are seen. Apoptosis at the end segments of some fibers was observed with apoptotic bodies forming vacuoles of different diameters (Figure 1(B)), appearing beneath basement membrane. Some of the bodies showed chromatin condensations while others exhibited only sarcoplasmic debris. Partition of other atrophied areas of fibers was also seen showing the fragments rests of contractile and sarcotubular systems, mitochondria, autophagosomes and lipofuscin granules 
(Figure 2(A)). The initiation of the apoptotic process is shown in Figure 2(B) where the partition of a very atrophied fiber produces different fragments, exhibiting most mitochondria with a normal morphology, lysosomes, a lipofuscin granule and isolated myofilaments. One of the fragments shows an indentated nucleus with the hetrochromatin located peripherally and possibly may represent a satellite cell because of complete absence of myofilaments and the presence of a centriole next to the nucleus. Additionally to the presence of myofilaments and mitochondria, some muscle fiber fragments presented autophagosomes of distinct complexity (Figure 3(A) and Figure 3(B)).
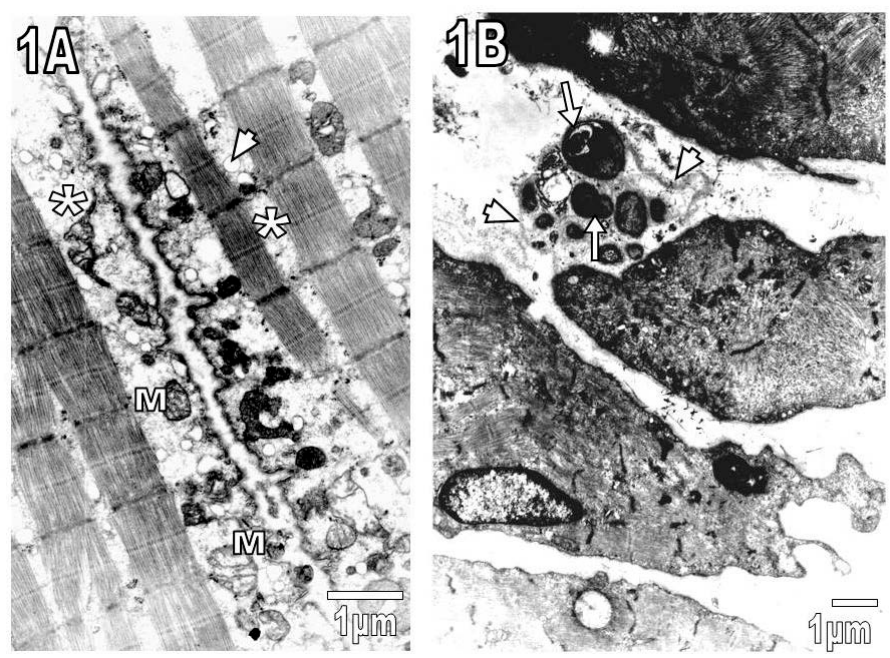

Figure 1. (A) Section of skeletal muscle fiber. Asterisks: subsarcolemmal and intermyofibrillar spaces, M: mitochondria, arrowhead: vesicles from tubular system elements. Magnification: 24,000×; (B) Section of atrophied skeletal muscle fiber. Arrows: apoptotic bodies, arrowheads: basement membrane. Magnification: 12,000×.

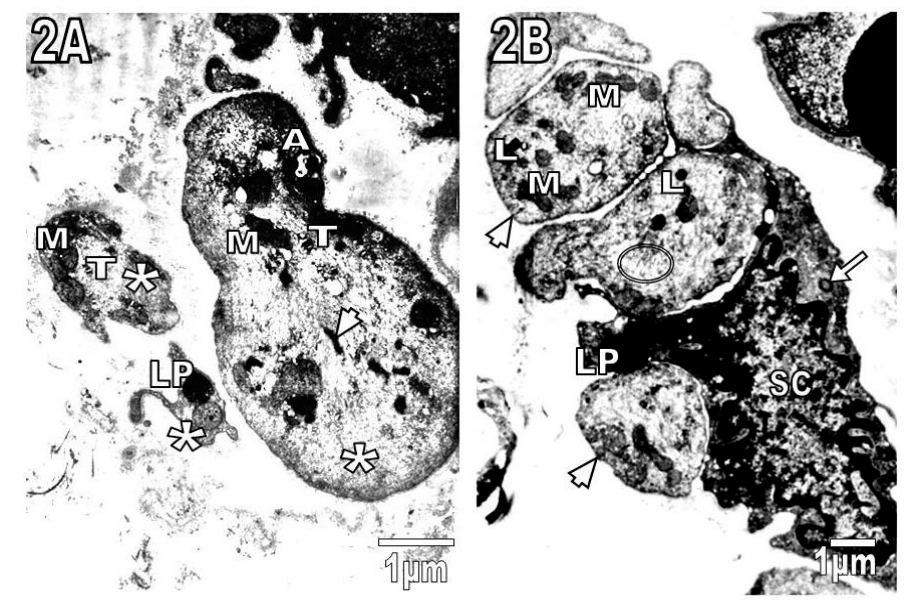

Figure 2. (A) Fragments of skeletal muscle fibers (asterisks) with organelles and rests of myofibrils (arrowhead). A: autophagosome, M: mitochondria, T: triads (elements of sarcotubular system), LP: lipofuscin granule. Magnification: 24,000×; (B) Section of atrophied skeletal muscle fiber. Arrowheads: muscle fiber fragments, M: mitochondria, LP: lipofuscin granule, L: lysosomes, circle: myofilaments, SC: satellite cell, arrow: centriole. Magnification: $16,000 \times$. 


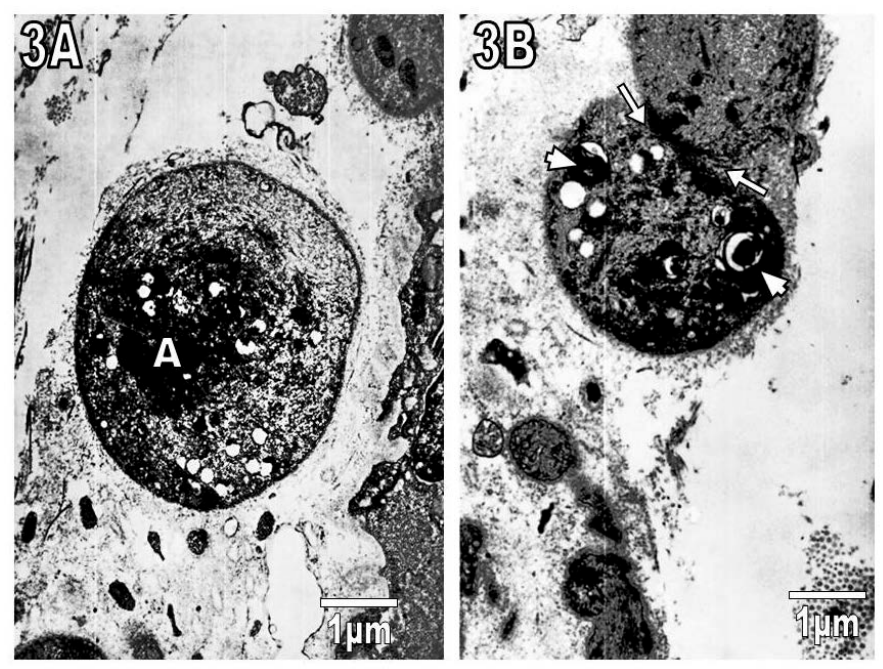

Figure 3. (A) Section of fragment of skeletal muscle fiber. A: autophagosome. Magnification: 24,000×; (B) Fragments of skeletal muscle fiber. Arrowheads: complex autophagosomes, arrows: partition of fiber. Magnification: $24,000 \times$.

\section{Discussion}

Apoptosis has been studied in the rheumatic diseases, rheumatoid arthritis (RA) and systemic lupus erythematosus (SLE). The presence of apoptotic cell death was confirmed in synoviocytes using DNA extraction and electrophoresis, electron microscopic analysis and DNA Nick end labelling (TUNEL assay) [13]. In SLE patients with augmented inflammatory, activity and/or the dominance signaling through $\gamma c$-chain cytokine receptors is affected, conducing to facilitated apoptosis of activated lymphocytes [14]. Additionally, changes in redox status and increased lymphocyte apoptosis have been associated with the development of SLE [15]. In SLE and RA, myositis has been described [9] [10] [16], but an apoptotic process had not been observed. On the contrary, activation of autophagia and suspended apoptosis were reported in IBM [4], and in other idiopathic inflammatory myopathies, several studies have failed to detect apoptosis in inflamed muscle tissue [1] [3] [17]. Apoptotic cells detected by TUNEL method in skeletal muscle biopsies from patients with PM were identified as infiltrating cells. It has been considered surprising because PM-affected skeletal muscle is known to be invaded by cytotoxic T lymphocytes [18] [19], that are capable of provoking apoptosis of target cells. It has been suggested as mechanism of this resistance to classical apoptosis in skeletal muscle cells of patients with myositis the expression of the antiapoptotic molecule FLICE (Fas-associated death domain-like IL-1-converting enzyme)-inhibiting protein (FLIP) in muscle fibers and on infiltrating lymphocytes of myositis biopsies [2]. But at least in the case of TUNEL staining, several studies have shown that it cannot always be possible to distinguish apoptotic and necrotic fibers [20] [21]. Despite its well-accepted status, TUNEL method is not usually used as the only apoptosis assay and is frequently paired with other assay [22]. On the contrary, distinction of a dying cell as apoptotic is considered irrefutable if the cell meets ultrastruc- 
tural criteria using a conventional transmission electron microscope [22].

The observed apoptotic process in SS inflammatory myopathy at the end segment of skeletal muscle fiber with elimination of nucleus would correspond to the so called "apoptotic nuclear death" [23] which certainly does not implicate the death of the entire multinucleate muscle cell. Nevertheless, the partition of a complete atrophied skeletal fiber was seen in the present work and described in Figure 2(B), which means that this type of multinucleated cell exhibits both the apoptotic nuclear death and the destruction of the entire cell as in mononucleated cell apoptosis. It is interesting to point out that the preservation of basement membrane as we saw in apoptosis at the end fiber segment has also been described in the skeletal muscle regenerative process [24] [25].

Our results would constitute the first ultrastructural report of apoptosis in SS inflammatory myopathy and would emphasize the importance of transmission electron microscopy in the study of apoptosis although one of its disadvantage is that only a small portion of sample can be observed at one time [22].

\section{References}

[1] Migheli, A., Mongini, T., Doriguzzi, C., Chiado-Piat, L., Piva, R., Ugo, I. and Palmucci, L. (1997) Muscle Apoptosis in Humans Occurs in Normal and Denervated Muscle, but Not in Myotonic Dystrophy, Dystrophinopathies or Inflammatory Disease. Neurogenetics, 1, 81-87. https://doi.org/10.1007/s100480050012

[2] Nagaraju, K., Casciola-Rosen, L., Rosen, A., Thomson, C., Loeffler, L., Parker, T., Danning, C., Rochon, P., Guillespie, J. and Plotz, P. (2000) The Inhibition of Apoptosis in Myositis and Normal Muscle Cells. The Journal of Immunology, 164, 5459-5465. https://doi.org/10.4049/jimmunol.164.10.5459

[3] Behrens, L., Bender, A., Johnson, M. and Hohlfeld, R. (1997) Cytotoxic Mechanisms in Inflammatory Myopathies. Co-Expression of Fas and Protective Bcl-2 in Muscle Fibres and Inflammatory Cells. Brain, 120, 929-938.

https://doi.org/10.1093/brain/120.6.929

[4] Girolamo, F., Lia, A., Amati, A., Strippoli, M., Coppola, C., Dragone, T., Trojano, M., Serlenga, L. and Roncali, L. (2012) Activation of Autophagy and Suspended Apoptosis in Skeletal Muscle of Inclusion Body Myositis. Italian Journal of Anatomy and Embryology, 117, 82.

[5] Navratil, J. and Ahearn, J. (2000) Apoptosis and Autoimmunity: Complement Deficiency and Systemic Lupus Erythematosus Revisited. Current Rheumatology Reports, 2, 32-38. https://doi.org/10.1007/s11926-996-0066-7

[6] Utz, P. and Anderson, P. (1998) Posttranslational Protein Modifications, Apoptosis, and the Bypass of Tolerance to Autoantigens. Arthritis \& Rheumatology, 41, $1152-1160$. https://doi.org/10.1002/1529-0131(199807)41:7<1152::AID-ART3>3.0.CO;2-L

[7] Rosen, A. and Casciola-Rosen, L. (2009) Autoantigens in Systemic Autoimmunity: Critic Partner in Pathogenesis. Journal of Internal Medicine, 265, 625-631. https://doi.org/10.1111/j.1365-2796.2009.02102.x

[8] Rosen, A. and Casciola-Rosen, L. (1999) Autoantigens as Substrates for Apoptotic Proteases: Implications for the Pathogenesis of Systemic Autoimmune Disease. Cell Death and Differentiation, 6, 6-12. https://doi.org/10.1038/sj.cdd.4400460

[9] Finol, H.J., Müller, B., Montes de Oca, I. and Márquez, A. (1988) Ultrastructure of 
Skeletal Muscle in Rheumatoid Myositis. The Journal of Rheumatology, 15, 552-555.

[10] Finol, H.J., Montagnani, S., Márquez, A., Montes de Oca, I. and Müller, B. (1990) Ultrastructural Pathology of Skeletal Muscle in Systemic Lupus Erythematosus. The Journal of Rheumatology, 17, 210-219.

[11] Finol, H.J., Márquez, A., Rivera, H., Montes de Oca, I. and Müller, B. (1994) Ultrastructure of Systemic Sclerosis Inflammatory Myopathy. Journal of Submicroscopic Cytology and Pathology, 26, 245-253.

[12] Subcommittee for Scleroderma Criteria of the American Rheumatism Association Diagnostic and therapeutic Criteria Committee (1980) Preliminary Criteria for the Classification of Systemic Sclerosis (Scleroderma). Arthritis \& Rheumatology, 23, 581-590. https://doi.org/10.1002/art.1780230510

[13] Nakajima, T., Aono, H., Hasunuma, T., Yamamoto, K., Shirai, T., Hirohata, K. and Nishiota, K. (1995) Apoptosis and Functional Fas Antigen in Rheumatoid Arthritis Synoviocytes. Arthritis \& Rheumatology, 38, 485-491. https://doi.org/10.1002/art.1780380405

[14] Lorenz, H.-M., Grünke, M., Hieronymus, T., Winkler, S., Blank, N., Rascu, A., Wendler, J., Geiler, T. and Kalden, J.R. (2002) Hyporesponsiveness to $\gamma c$-Chain Cytokines in Activated Lymphocytes from Patients with Systemic Lupus Erythematosus Leads to Accelerated Apoptosis. European Journal of Immunology, 32, 1253-1263.

https://doi.org/10.1002/1521-4141(200205)32:5<1253::AID-IMMU1253>3.0.CO;2-\#

[15] Shah, D., Sah, S., Wanchu, A., Wu, M.X. and Bhatnagar, A. (2013) Altered Redox State and Apoptosis in the Pathogenesis of Systemic Lupus Erythematosus. Immunobiology, 218, 620-627. https://doi.org/10.1016/j.imbio.2012.07.030

[16] de Palma, L., Chillemi, C., Albanelli, S., Rapali, S. and Bertoni-Freddari, C. (2000) Muscle Involvement in Rheumatoid Arthritis: An Ultrastructural Study. Ultrastructural Pathology, 24, 151-156. https://doi.org/10.1080/01913120050132886

[17] Olivé, M., Martinez-Matos, J., Montero, J. and Ferrer, I. (1997) Apoptosis Is Not the Mechanism of Cell Death of Muscle Fibers in Human Muscular Dystrophies and Inflammatory Myopathies. Muscle \& Nerve, 20, 1328-1330. https://doi.org/10.1002/(SICI)1097-4598(199710)20:10<1328::AID-MUS20>3.0.CO; $2-\mathrm{Y}$

[18] Dalakas, M. (1991) Polymyositis, Dermatomyositis, and Inclusion-Body Myositis. The New England Journal of Medicine, 325, 1487-1498. https://doi.org/10.1056/NEJM199111213252107

[19] Iannone, F., Cauli, A., Yanni, G., Kingsley, G.H., Isenberg, D., Corrigall, V. and Panayi, G. (1996) T-Lymphocyte Immunophenotyping in Polymyositis and Dermatomyositis. Rheumatology, 35, 839-845. https://doi.org/10.1093/rheumatology/35.9.839

[20] Grasl-Kraupp, B., Ruttkay-Nedecky, B., Koudelka, H., Bukowska, K., Bursch, W. and Schulte-Hermann, R. (1995) In Situ Detection of Fragmented DNA (TUNEL Assay) Fails to Discriminate among Apoptosis, Necrosis, and Autolytic Cell Death: A Cautionary Note. Hepatology, 21, 1465-1468.

[21] Schaper, J., Elsässer, A. and Kostin, S. (1999) The Role of Cell Death in Heart Failure. Circulation Research, 85, 867-869. https://doi.org/10.1161/01.RES.85.9.867

[22] Watanabe, M., Hitomi, M., van der Wee, K., Rothenberg, F., Fisher, S., Zucker, R., Svoboda, K., Goldsmith, E., Heiskanen, K. and Nieminen, A.-L. (2002) The Pros and Cons of Apoptosis Assays for Use in the Study of Cells, Tissues, and Organs. 
Microscopy and Microanalysis, 8, 375-391.

https://doi.org/10.1017/S1431927602010346

[23] Dupont-Versteegden, E. (2006) Apoptosis in Skeletal Muscle and Its Relevance to Atrophy. World Journal of Gastroenterology, 12, 7463-7466.

https://doi.org/10.3748/wjg.v12.i46.7463

[24] Allbrook, D. (1962) An Electron Microscopic Study of Regenerating Skeletal Muscle. Journal of Anatomy, 96, 137-152.

[25] Fuenmayor, D., Finol, H. and Ogura, M. (1973) Aspectos ultraestructurales del proceso regenerativo en el músculo caudal del reptil Cnemidophoruslemniscatus. Acta Científica Venezolana, 24, 88-94. 